\title{
ANALISIS AKUNTABILITAS PENGELOLAAN ALOKASI DANA DESA (ADD) DI KECAMATAN CANDIPURO KABUPATEN LUMAJANG
}

\author{
Vilmia Farida*, A. Waluya Jati, Riska Harventy \\ Program Study Akuntansi Fakultas Ekonomi Dan Bisnis \\ Universitas Muhammadiyah Malang \\ Jl. Raya Tlogomas No. 246 Malang \\ Corresponding author: faridavilmia@gmail.com
}

\begin{abstract}
The purpose of this research is to analyze the accountability of Village Fund Allocation management in Candipuro District, Lumajang Regency which consists of planning, implementation, reporting and accountability. This research was conducted in ten villages in the Candipuro District. Data collection techniques were carried out by using documentation and interview techniques. The analysis technique used is descriptive analysis with a qualitative approach.

The results of this study indicate that in the District of Candipuro at the planning, implementation and reporting stages have implemented the principles of accountability and the principle of transparency. whereas at the accountability stage it is good enough even though there is one village that is physically not yet accountable because the construction has not yet been completed.
\end{abstract}

Keyword: Accountability, ADD, Finance

\section{PENDAHULUAN}

Akuntabilitas merupakan prinsip yang harus ada dalam pemerintahan baik pemerintahan yang terbesar maupun pemerintahan yang kecil yaitu pemerintahan desa. Sebuah pemerintahan dikatakan baik apabila masyaratnya sejahtera dan tingkat kesejahteraan dilihat dari unit yang paling kecil yaitu desa. Akuntabilitas pemerintahan desa merupakan sebuah tolok ukur kemampuan pemerintah dalam melaksanakan tanggungjawabnya dalam kegiatan pembangunan terkait masalah keuangan yang telah disusun dalam APPBDes dan Alokasi Dana Desa merupakan salah satu komponen di dalamnya. Alokasi Dana Desa merupakan

Diterima 8 Sep 2018

Direviu 14 Sep 2018 Direvisi 5 Okt 2018 Diterima 20 Okt 2018

Artikel ini tersedia di website :

http://ejournal.umm. ac.id/index.php/jaa dana perimbangan dari kabupaten yang kemudian akan disebar ke desa-desa.

Kabupaten Lumajang menyusun anggaran Alokasi Dana Desa yang kemudian selanjutnya akan disalurkan ke setiap kecamatan yang ada. Salah satunya yaitu Kecamatan Candipuro yang dibagi menjadi 10 Desa yaitu: Jugosari, Jarit, Candipuro, Sumberejo, Sumberwuluh, Sumbermujur, Penanggal, Tambahrejo, Kloposawit dan Tumpeng yang terletak tidak jauh dari ibu kota. Permasalahan yang umumnya sering terjadi tentang Alokasi Dana Desa yaitu sekretaris desa belum membuat Laporan pertanggungjawaban Pengeluaran, Register penutupan kas belum dibuat oleh Bendahara Pengeluaran, adanya Barang Milik Daerah yang penyaluranya belum 
tertib, Pengguna Anggaran belum menunjuk PPK dan menetapkan PPTK, penggunaan Pribadi Dana APBDes yang dilakukan oleh perangkat desa.

Penelitian ini dilakukan pada sepuluh desa di Kecamatan candipuro. Penerapan prinsip akuntabilitas pengelolaan Alokasi Dana Desa (ADD) dari tahap perencanaan, pelaksanaan, pelaporan pengelolaan ADD diharapkan dapat dipertanggungjawabkan. Jika pemerintahan desa dapat mempertangguang jawabkan pengelolaan Alokasi Dana Desa dengan baik sesuai dengan asas-asas Akuntabilitas dan prinsip-prinsip Akuntabilitas maka dapat mendorong pemerintahan yang baik (good governance) karena mendekatkan negara kepada masyarakat sekaligus meningkatkan partisipasi masyarakat yang akhirnya mendorong akuntabilitas dan transparansi.

\section{LITERATUR REVIU}

\section{Alokasi Dana Desa}

Alokasi Dana Desa (ADD) merupakan dana perimbangan yang bersumber dari APBD yang hrus dialokasikan oleh pemerintah Kabupaten untuk desa-desa. Dalam pengelolaan Alokasi Dana desa kabupaten membentuk tim fasilitas, yang memfasilitasi pengelolaan Alokasi Dana Desa dan kemudian membentuk tim pendamping di kecamatan yang mendampingijalannya pengelolaan Alokasi Dana Desa dan kemudian membentuk Tim pelaksana di Desa yang memiliki tanggungjawab sebagai pelaksana pengelolaan Alokasi Dana Desa. (Sanusi 20 14: 78).

\section{Pengelolaan Keuangan Desa}

Menurut undang-undang nomor 32 tahun 2004 tentang pengelolaan keuangan desa, keuangan desa merupakan hak dan kewajiban pemerintah desa dalam rangka penyelenggaraan desa. Keuangan desa merupakan kekayaan desa yang berhubungan langsung dengan hak dan kewajiban desa. Pengelolaan keuangan desa dimulai dari tahap perencanaan, pelaksanaan, sampai dengan tahap pelaporan harus dapat dipertanggungjawabkan.

Kepala desa memiliki wewenang dalam penyelenggaraan seluruh pengelolaan keuangan desa karena kepala desa adalah pemegang kekuasaan pengelolaan keuangan. Sedangkan perangkat desa merupakan pelaksana teknis dalam kegiatan pengelolaan keuangan. Perangkat desa ditujuk langsung oleh kepala desa untuk pengelolaan keuangan desa. Perangkat desa harus kompeten dalam melakukan tanggungjawabnya sebagai peaksana pengelolaan keuangan desa. Keuangan desa harus dikelola berdasarkan asas-asas Akuntabilitas serta dilakukan dengan tertib dan disiplin anggaran. 
Prinsip-prinsip yang mendasari pengelolaan keuangan daerah, yaitu:

a. Prinsip transparansi atau keterbukaan,

Transparansi merupakan hal yang paling dibutuhkan dalam pemerintahan. Trannspransi dalam pemerintahan yaitu keterbukaan pemerintah dalam membuat kebijakan-kebijakan keuangan yang dapat dengan mudah. Transparansi dalam pemerintahan harus memiliki timbal balik dengan masyarakatnya sehingga tercipta pemerintah daerah yang bersih, efektif dan efisien, akuntabel, dan responsif terhadap aspirasi dan kepentingan masyarakat.

b. Prinsip akuntabilitas

Akuntabilitas merupakan pertanggaungjawaban publik artinya semua kegiatan yang menyangkut dengan urusan publik harus dapat dipertanggungjawabkan baik mulai dari perencanaan, pelaksanaan sampai dengan pelaporan harus dapat di pertanggungjawabkan kepada masyaratat dan pengawas keuangan. Masyarakat tidak hanya berhak mengetahui tentang pengelolaan keuangan pemerintah. Namun, masyarakat juga dapat menuntut tanggungjawab pemerintah terkait dengan pengelolaan keuangan tersebut.

c. Kejujuran dalam pengelolaan keuangan publik (probity)

Kejujuran dalam pengelolaan keuangan publik sangat di junjung tinggi oleh karena itu pengelolaan keuangan harus dilakukan oleh staf yang dapat dipercaya dan memiliki kemampuan yang kompeten dalam melakukan tanggungjawabnya sebagai pengelola keuangan. Dengan adanya hal tersebut dapat meminimalisir terjadinya kecurangan.

\section{Asas-Asas Alokasi Dana Desa}

a. Pengelolaan keuangan desa berpedoman pada RPJMDesa, RKPDesa, dan daftar usulan RKPDesa yang dituangkan dalam APBDesa

b. Keuangan Desa dikekolola berdasarkan asas-asas transparansi, akuntabel partisipatif serta dilakukan dengan tertib dan disiplin anggaran.

c. Pengelolaan keuangan desa sebagaimana dimaksud pada huruf (1), dikelola dalam masa 1 (satu) tahun anggaran yakni mulai tanggal 1 Januari sampai dengan tanggal 31 Desember.

Seluruh kegiatan yang berhubungan dengan pengelolaan keuangan desa harus dapat dipertanggungjawabkan dan dikembangkan secara berkelanjutan dengan upaya pemeliharaan melalui partisipasi masyarakat. 
Perencanaan, Pelaksanaan, Pelaporan, dan Pertanggungjawaban Alokasi Dana Desa (ADD)

Menurut Peraturan pemerintah dalam negeri nomor 113 tahun 2014 tentang pengelolaan keuangan desa adalah sebagai berikut

\section{a. Perencanaan ADD}

Pada tahap perencanaan Alokasi Dana Desa, sekretaris Desa Menyusun Rancangan Peraturan Desa berdasarkan RKPDesa tahun anggaran yang kemudian menyampaikan Rancangan Peraturan Desa tersebut kepada kepala Desa. Setelah kepala desa menerima Rancangan peraturan desa dan menyetujuinya, kepala desa menyampaikan Rancangan Peraturan desa kepada Badan Permusyawarata Desa untuk dilakukan pembahasan dan disepakati bersama.

\section{b. Pelaksanaan ADD}

Pada pelaksanaan Alokasi Desa penerimaan dan pengeluaran desa harus dilaksanakan melalui rekening kas desa sesuai dengan kewenangan desa. Seluruh kegiatan keuangan harus dilakukan sesuai dengan kewenangan dan melalui layanan perbankan, kecuali bagi desa yang tidak meemiliki pelayanan perbankan maka pengaturan nya dilakukan oleh pemerintah kabupaten. Seluruh kegiatan penerimaan dan prngrluaran kas harus disertai bukti yang lengkap dan sah.

\section{c. Pelaporan}

Pelaporan Alokasi Dana Desa dilakukan setiap 4 bulan sekali yaitu melalui muyawarah yang dilakukan pemerintah desa dengan masarakat. Pelaporan dilakukan karena pelaporan merupakan salah satu bentuk tanggungjawab pemerintah desa dalam mengelola keuangan desa. Pelaporan yang dilakukan dapat dgunakan sebagai media evaluasiatas pelaksanaan kegiatan desa yang di danai dengan alokasi dana desa. Pelaporan kegiatan yang didanai oleh Alokasi Dana Desa merupakan salah satu kewajiban pemerintah desa dalam pengelolaan keuangan desa. Bentuk pelporan kegiatan yang di danai ADD adalah laporan SPJ yang diberikan pada Kabupaten dengan persetujuan dari Kecamatan. Laporan SPJ berisi daftar perencanaan program atau kegiatan yang dibiayai oleh ADD hingga bukti-bukti dokumentasi dan apapun yang berhubungan dengan program yang dibiayai ADD.

\section{d. Pertanggungjawaban ADD}

Seorang kepala desa harus menyampaikan laporan pertanggungjawaban realisasi anggara setiap akhir tahun kepada Bupati. Laporan 
pertanggungjawaban ini dibuat dengan tujuan sebagai bentuk kewajiban aparat desa dalam melaksanaan kewajiban mereka. Laporan realilsasi anggaran berisi pendapatan, belanja, dan pembiayaan. Pembuatan Laporan realisasi angaran dibuat berdasarkan peraturan desa. Pada Peraturan Desa tentang laporan pertanggungjawaban realisasi pelaksanaan APBDesa harus dilampiri Format Laporan Pertanggungjawaban Realisasi Pelaksanaan APBDesa Tahun Anggaran berkenaan, Format Laporan Kekayaan Milik Desa per 31 Desember Tahun Anggaran berkenaan, dan format Laporan Program Pemerintah dan Pemerintah Daerah yang masuk ke desa.

Hasil penelitian Irma (2015) tentang Akuntabilitas Pengelolaan Alokasi Dana Desa (ADD) di Kecamatan Dolo Selatan Kabupaten Sigi, dengan jenis penelitian deskriptif dengan menggunakan pendekatan kualitatif. Hasil penelitian Akuntabilitas pengelolaan Alokasi Dana Desa di wilayah Kecamatan Dolo Selatan Kabupaten Sigi dilihat dari tahap perencanaan, pelaksanaan dan pertanggung jawaban baik secara teknis maupun administrasi sudah berjalan dengan baik, namun dalam hal pertanggung jawaban administrasi keuangan kompetensi sumber daya manusia pengelola masih merupakan kendala utama, sehingga masih memerlukan pendampingan dari aparat Pemerintah Daerah Kabupaten Sigi.

Hasil penelitian Fajri dan Siswidiyanto (2015) dengan judul penelitian Akuntabilitas Pengelolaan Alokasi Dana Desa (ADD) (Studi pada Kantor Desa Ketindan, Kecamatan Lawang, Kabupaten Malang) menggunkan jenis Penelitian deskriptif dengan pendekatan kualitatif, Hasil penelitiannya yaitu Akuntabilitas pemerintah desa pada pengelolaan ADD di Desa Ketindan melalui 3 tahapan yaitu mulai dari tahap perencanaan, pelaksanaan hingga pelaporan. Dimana ketiga-tiganya dilaksanakan pemerintah desa sebagai dasar komitmen pemerintah desa dalam penyelenggaraan pengelolaan keuangan khususnya pengelolaan ADD. Dari setiap tahapan tersebut telah dilaksanakan dengan mematuhi setiap aturan yang tertera dan tertulis dalam Peraturan Bupati

\section{METODE}

Penelitian ini merupakan penelitian deskriptif dengan pendekatan kualitatif dengan mengambil objek yaitu Kecamatan candipuro di Kabupaten Lumajang. Data diperoleh langsung dari Kecamatan Candipuro dengan menggunakan teknik dokumentasi dan dengan melakukan wawancara pada narasumber yang bersangkutan. Analisis data dilakukan dengan tahapan sebagai berikut: 
1. Menganalisis perencanaan Alokasi Dana Desa (ADD) di kecamatan Candipuro dengan hasil dokumen yang diperoleh yaitu APBDes dan daftar hadir musrenbangdes dan menganalisis kesesuaian dokumen yang diperoleh dengan Peraturan Pemerintah Dalam Negeri nomor 113 tentang pengelolaan keuangan desa.

2. Menganalisis pelaksanaan Alokasi Dana Desa (ADD) di kecamatan Candipuro dengan hasil dokumen yang diperoleh yaitu Laporan Realisasi Anggaran dan Papan informasi, Banner dan website sebagai media penyampai informasi dan menganalisis kesesuaian dokumen tentang pelaksanaan dengan Peraturan Pemerintah Dalam Negeri nomor 113 tentang pengelolaan keuangan desa.

3. Menganalisis pelaporan Alokasi Dana Desa (ADD) di kecamatan Candipuro dengan hasil data yang diperoleh yaitu Laporan SPJ dan Laporan Realisasi Anggaran dan menganalisis kesesuaian dokumen tentang pelaporan dengan Peraturan Pemerintah Dalam Negeri nomor 113 tentang pengelolaan keuangan desa.

4. Menganalisis pertanggungjawaban Alokasi Dana Desa (ADD) di kecamatan Candipuro dan menganalisis kesesuaian dokumen yang diperoleh dengan Peraturan Pemerintah Dalam Negeri nomor 113 tentang pengelolaan keuangan desa.

5. Perumusan dalam simpulan tentang hasil yang telah di dapat tentang Akuntabilitas Pengelolaan Alokasi Dana Desa di Kecamatan Candipuro Kabupaten Lumajang

\section{HASIL DAN PEMBAHASAN}

\section{a. Perencanaan}

Tabel 1

Tingkat Kehadiran Musrebangdes tahun 2016

\begin{tabular}{|l|l|l|l|l|}
\hline No. & \multicolumn{1}{|c|}{ Desa } & Undangan & Kehadiran & \multicolumn{1}{c|}{$\%$} \\
\hline $\mathbf{1 .}$ & Jugosari & 50 & 45 & $90 \%$ \\
\hline $\mathbf{2 .}$ & Jarit & 45 & 45 & $100 \%$ \\
\hline $\mathbf{3 .}$ & Candipuro & 55 & 53 & $96 \%$ \\
\hline $\mathbf{4 .}$ & Sumberejo & 60 & 59 & $97 \%$ \\
\hline $\mathbf{5 .}$ & Sumberwuluh & 65 & 64 & $98 \%$ \\
\hline $\mathbf{6 .}$ & Sumbermujur & 85 & 85 & $100 \%$ \\
\hline $\mathbf{7 .}$ & Penanggal & 75 & 73 & $97 \%$ \\
\hline $\mathbf{8 .}$ & Tambahrejo & 56 & 56 & $100 \%$ \\
\hline $\mathbf{9 .}$ & Kloposawit & 60 & 60 & $100 \%$ \\
\hline $\mathbf{1 0 .}$ & Tumpeng & 30 & 28 & $98 \%$ \\
\hline
\end{tabular}


Jika dilihat dari datar hadir masyarakat pada forum diskusi Musrenbangdes menunjukkan bahwa masyarakat desa pada kecamatan Candipuro sangat partisipatif. Jika dilihat dari jumlah undangan yang telah disebar dengan daftar hadir masyarakat rata-rata tingkat kehadiran masyarakat dalam forum diskusi ini 90\% ke atas. Hal tersebut dapat menunjukkan bahwa masyarakatnya cukup partisipatif dalam menghadiri forum diskusi tersebut meskipun beberapa tokoh masyarakat ada yang tidak dapat mengikuti jalannya musyawarah. Hal ini diperkuat oleh pernyataan salah satu informan yang mengatakan:

"Musrenbangdes merupakan sarana masyarakat untuk menyampaikan aspirasi masyarakat untuk melakukan kegiatan pembangunan dan disana semua usulan-usulan kami tampung dan memvoting usulan yang paling mendesak kami dahulukan dan usulan-usulan masyarakat yang belum terlaksana dimasukkan dalam rencana pembangunan pada tahun berikutnya.”

(Hasil wawancara dengan sekdes Jarit, pada tanggal 13 Maret 2018)

\section{b. Pelaksanaan}

Tabel 2

Tabel Informasi ADD

\begin{tabular}{|l|l|l|}
\hline No. & Desa & Informasi ADD \\
\hline $\mathbf{1 .}$ & Jugosari & Papan informasi \\
\hline $\mathbf{2 .}$ & Jarit & Banner \\
\hline $\mathbf{3 .}$ & Candipuro & Bannner \\
\hline $\mathbf{4 .}$ & Sumberejo & Papan Informasi \\
\hline $\mathbf{5 .}$ & Sumberwuluh & Banner \\
\hline $\mathbf{6 .}$ & Sumbermujur & Papan Informasi \\
\hline $\mathbf{7 .}$ & Penanggal & Papan Informasi \\
\hline $\mathbf{8 .}$ & Tambahrejo & Banner \\
\hline $\mathbf{9 .}$ & Kloposawit & Banner \\
\hline
\end{tabular}

Pelaksanaan Alokasi Dana Desa pada Kecamata Candipuro Kabupaten Lumajang telah melaksanakan prinsip transparansi. tersebut telah sesuai dengan prinsip transparansi dibuktikan dengan "pemerintahan dikatakan dengan transparan apabila pelaksanaan dilakukan secara terbuka dan masyarakat dapat mengakses informasi tersebut dengan mudah”. Desa-desa di kecamatan candipuro menggunakan papan informasi dan banner sebagai alat menyampaikan informasi kepada masyarakat.

Hal tersebut diperkuat dengan hasil wawancara dengan informan berikut:

"Kita menggunakan papan pengumuman dan banner seperti pelaksanaan dan program-program, banner dan informasi-informasi yang telah dipampang 
jika telah melewati periode anggaran akan di lepaskan dan diganti dengan yang baru ."

(Hasil wawancara dengan kades Sumberwuluh, pada tanggal 12 Maret 2018)

\section{c. Pelaporan}

Tabel 3

Kelengkapan dokumen 2016

\begin{tabular}{|c|c|c|c|c|c|c|}
\hline No & Desa & $\begin{array}{c}\text { Dokument } \\
\text { asi hasil } \\
\text { pelaksanaa } \\
\mathrm{n}\end{array}$ & $\begin{array}{c}\text { Realisasi } \\
\text { biaya dan } \\
\text { bukti } \\
\text { pembayar } \\
\text { an }\end{array}$ & $\begin{array}{c}\text { Foto } \\
\text { kegiatan } \\
\text { Infrastruk } \\
\text { ture }\end{array}$ & $\begin{array}{c}\text { Foto } \\
\text { peran } \\
\text { masyaraka } \\
\text { t }\end{array}$ & $\begin{array}{c}\text { Kelengka } \\
\text { pan } \\
\text { dokumen }\end{array}$ \\
\hline 1. & Jugosari & $\sqrt{ }$ & $\sqrt{ }$ & $\sqrt{ }$ & $\sqrt{ }$ & Lengkap \\
\hline 2. & Jarit & $\sqrt{ }$ & $\sqrt{ }$ & $\sqrt{ }$ & $\sqrt{ }$ & Lengkap \\
\hline 3. & Candipuro & $\sqrt{ }$ & $\sqrt{ }$ & $\sqrt{ }$ & $\sqrt{ }$ & Lengkap \\
\hline 4. & Sumberejo & $\sqrt{ }$ & $\sqrt{ }$ & $\sqrt{ }$ & $\sqrt{ }$ & Lengkap \\
\hline 5. & Sumberwuluh & $\sqrt{ }$ & $\sqrt{ }$ & $\sqrt{ }$ & $\sqrt{ }$ & Lengkap \\
\hline 6. & Sumbermujur & $\sqrt{ }$ & $\sqrt{ }$ & $\sqrt{ }$ & $\sqrt{ }$ & Lengkap \\
\hline 7. & Penanggal & $\sqrt{ }$ & $\sqrt{ }$ & $\sqrt{ }$ & $\sqrt{ }$ & Lengkap \\
\hline 8. & Tambahrejo & $\sqrt{ }$ & $\sqrt{ }$ & $\sqrt{ }$ & $\sqrt{ }$ & Lengkap \\
\hline 9. & Kloposawit & $\sqrt{ }$ & $\sqrt{ }$ & $\sqrt{ }$ & $\sqrt{ }$ & Lengkap \\
\hline 10. & Tumpeng & $\sqrt{ }$ & $\sqrt{ }$ & $\sqrt{ }$ & $\sqrt{ }$ & Lengkap \\
\hline
\end{tabular}

Pelaporan Dana Desa pada Kecamatan Candipuro telah memenuhi peraturan yang berlaku dan sudah cukup akuntabel. Sesuai dengan asas-asas 2 yaitu "Keuangan Desa dikelola berdasarkan asas-asas transparansi, akuntabel partisipatif serta dilakukan dengan tertib dan disiplin anggaran”.

Laporan SPJ setiap desa telah dilampiri dokumen-dokumen pendukung sesuai yang telah di tetapkan seperti yang telah di sebutkan diatas seperti foto kegiatan, dan bukti-bukti pembayaran seperti yang ada pada lampiran.

Hal tersebut dibuktikan dari hasil wawancara dengan informan yang mengatakan:

"Semua Alokasi Dana desa dapat dicairkan dengan memberikan laporan keuangan, laporan spj yang dengan ketentuan yang telah berlaku yaitu laporan harus dilampiri dengan penunjang, tentunya ada bukt transaksii, foto program kegiatan, foto proses ppembangunan.”

(Hasil wawancara dengan bendahara Tumpeng, pada tanggal 13 Maret 2018)

\section{d. Pertanggungjawaban}

Hasil-hasil pembangunan yang bersumber dari dana ADD di Kecamatan Candipuro Kabupaten Lumajang dapat dilihat pada tabel berikut : 
Tabel 4

Hasil Fisik yang dibangun dengan ADD Tahun 2016

\begin{tabular}{|c|c|c|c|}
\hline No. & Desa & Hasil Sarana dan prasarana & Kondisi \\
\hline \multirow[t]{4}{*}{1.} & \multirow[t]{4}{*}{ Jugosari } & Rehab Kantor Desa & Baik \\
\hline & & Pembangunan Paud & Baik \\
\hline & & Pembangunan Polindes & Baik \\
\hline & & Pembangunan Lapangan & Baik \\
\hline \multirow[t]{5}{*}{2.} & \multirow[t]{5}{*}{ Jarit } & Pembangunan paving jalan makam & Baik \\
\hline & & Rehab mushollah Bulak Klakah & Baik \\
\hline & & $\begin{array}{lll}\begin{array}{l}\text { Pembangunan } \\
\text { Kebonsari }\end{array} & \text { Paving } & \text { Dusun } \\
\end{array}$ & Baik \\
\hline & & Pembangunan Posyandu Kartini & Baik \\
\hline & & Rehab Balai Desa & Baik \\
\hline \multirow[t]{3}{*}{3.} & \multirow[t]{3}{*}{ Candipuro } & Pembangunan Pagar Makam & Baik \\
\hline & & Pembangunan Garasi Ambulan & Baik \\
\hline & & $\begin{array}{l}\text { Pembuatan pagar dan Pemasangan } \\
\text { Paving Polindes Dusun Panggung } \\
\text { Lombok Kidul }\end{array}$ & Baik \\
\hline 4. & Sumberejo & Renovasi Balai Desa & Belum Selesai \\
\hline 5. & Sumberwuluh & $\begin{array}{l}\text { Pemeliharaan Saranadan Prasarana } \\
\text { Balai Desa }\end{array}$ & Baik \\
\hline \multirow[t]{2}{*}{6.} & \multirow[t]{2}{*}{ Sumbermujur } & Pembangunan Drainase & Baik \\
\hline & & Rehab Kantor Pelayanan & Baik \\
\hline 7. & Penanggal & $\begin{array}{l}\text { Pengkerasan Burda Dusun Rekesan } \\
\text { Timur }\end{array}$ & Baik \\
\hline \multirow[t]{2}{*}{8.} & \multirow[t]{2}{*}{ Tambahrejo } & Renovasi Kantor Desa & Baik \\
\hline & & Renovasi Mushollah & Baik \\
\hline 9. & Kloposawit & Pembangunan Rabat & Baik \\
\hline \multirow{2}{*}{10.} & \multirow[t]{2}{*}{ Tumpeng } & Pembangunan saluran Drainaser & Baik \\
\hline & & Rehab Aula Desa & Baik \\
\hline
\end{tabular}

Dari data tersebut menunjukkan bahwa hasil yang dicapai di setiap desa rata-rata baik secara fisik dapat dipertanggungjawabkan meskipun ada satu desa yang melakukan renovasi balai desa tapi belum selesai. Renovasi balai desa terhambat karena kurangnya pekerja yang melakukan renovasi pembangunannya sehingga renovasi balai desa tidak dapat selesai pasda waktu yang telah di tentukan.

\section{SIMPULAN}

Hasil analisis data menunjukkan tahap perencanaan Alokasi Dana Desa (ADD) di sepuluh desa telah menerapkan asas-asas Akuntabilitas, prinsip partisipasi dan transparansi. hal tersebut dapat dilihat dari tingkat hadir masyarakat yang cukup partisipatif dalam mengikuti musyawarah.

Pada tahap pelaksanaan program Alokasi Dana Desa (ADD) di Kecamatan Candipuro telah menerapkan prinsip transparansi dan akuntabilitas. Hal tersebut dapat dilihat dari pelaksanaan program alokasi dana desa yang telah dipampang di papan informasi dan ada pula yang dijadikan banner. 
Pelaporan Alokasi Dana Desa (ADD) di Kecamatan Candipuro telah menerapkan asas-asas dan prinsip akuntabilitas sudah terlaksana sepenuhnya karena laporan yang terkait dengan ADD sudah lengkap.

Pertanggungjawaban Alokasi Dana Desa (ADD) secara fisik sudah cukup baik, meskipun ada satu desa yang pertanggungjawabannya secara fisik belum selesai rata-rata keseluruhan desa cukup akuntabel.

Berdasarkan penelitian yang telah dilakukan peneliti dapat memberikan saran kepada Kecamatan Candipuro agar dapat membangun pemerintahan lebih baik lagi. Saran dari peneliti untuk kecamatan Candipuro adalah sebagai berikut:

1. Pemerintah harus memberikan bimbingan lebih kepada tim pengelola Alokasi Dana Desa agar goals yang telah disusun dapat tercapai sesuai dengan target.

2. Pemerintah juga harus memberikan bimbingan lebih agar laporan yang disusun dengan standar yang sama agar lebih mudah memahaminya.

3. Pemerintah harus melakukan pelatihan tentang penyusunan laporan keuangan pada seluruh desa.

\section{DAFTAR PUSTAKA}

-2010. Seri Bunga Rampai Akuntansi Sektor Publik: Sistem Akuntansi Sektor Publik: Yogyakarta: UPP STIM YKPN

Arifiyanto, D.F dan Kurrohman, T. (2015). Akuntabilitas pengelolaan alokasi dana desa di Kabupaten Jember. Jurnal Riset Akuntansi dan KeuanganVolume 2 No.3. Hal. 457.

Fajri Rahmi dan Endah Setyowati (2015). Akuntabilitas pengelolaan alokasi dana desa Di Desa Ketindan, Kecamatan Lawang, Kabupaten Malang. Jurnal AdministrasiPublik (JAP) Vol. 3, No. 7. Hal. 1099

Peraturan Menteri Dalam Negeri Republik Indonesia Nomor 113 Tahun 2014 tentang Pengelolaan Keuangan Desa.

Undang-Undang Nomor 32 Tahun 2004 tentang Pemerintah Daerah.

Wahyuddin. (2016). Implementasi kebijakan alokasi dana desa di desa Ako Volume 4 Nomor 5. hal 143. 